\title{
Fast Atom Search Algorithm for Reactive Power Optimization of Power Grid with High-Penetration Wind and Solar Energies
}

\author{
Fang Zeng and Hongchun Shu ii \\ Faculty of Electric Power Engineering, Kunming University of Science and Technology, Kunming 650500, China \\ Correspondence should be addressed to Hongchun Shu; fanger1119@kust.edu.cn
}

Received 21 November 2020; Revised 30 November 2020; Accepted 8 December 2020; Published 18 December 2020

Academic Editor: Xiao-Shun Zhang

Copyright (C) 2020 Fang Zeng and Hongchun Shu. This is an open access article distributed under the Creative Commons Attribution License, which permits unrestricted use, distribution, and reproduction in any medium, provided the original work is properly cited.

\begin{abstract}
This paper constructs a reliable reactive power optimization (RPO) model of power grid with the controlled participation of highpenetration wind and solar energies and provides a novel fast atom search optimization (FASO) algorithm to reach a set of solutions to the RPO problem. The developed FASO algorithm owns prominent merits of high searching efficiency and premature convergence avoidance compared with the original atom search optimization (ASO) algorithm, which is applied to determine the optimal dispatch scheme including terminal voltage of generators, the capacity of static VAR compensator (SVC), reactive power output of wind and solar energies, and the tap ratio of transformers. There are two objective functions to be minimized for maintaining the safe and reliable operation of power grid, i.e., total power loss of transmission lines and total voltage deviation of nodes. Meanwhile, the regulation capacities of wind farms and photovoltaic (PV) stations are evaluated based on different weather conditions, i.e., wind speed and solar irradiation. Particularly, the reactive power outputs of wind and solar energies can be globally controlled to coordinate with other controllable units instead of a local self-control. Eventually, the extended IEEE 9-bus and IEEE 39-bus systems are introduced to test the performance of the FASO algorithm for RPO problem. It has been verified that FASO can not only meet the optimal regulation requirements of RPO but also obtain high-quality regulation schemes with the fastest convergence speed and highest convergence stability in contrast with else algorithms.
\end{abstract}

\section{Introduction}

Currently, the share of renewable energy sources (RESs) in the power grid is ever-increasing due to their relatively lowcost and sustainability features [1-3]. However, RESs such as wind energy [4-8] and solar energy [9-13] are intermittent and stochastic in their nature, of which the high-proportion integration into the power grid poses a great challenge on the stable operation of the whole power grid while brings new opportunities for reactive power optimization (RPO) [14-16]. Actually, RESs not only satisfy active power demand on the power grid but also have definite potential in reactive power regulation $[17,18]$. In recent years, RPO has increasingly been a highlighted research focus in power system programming issues for practical engineering applications [19-21]. Generally, RPO is devoted to improve the voltage quality of nodes and reduce the total power loss of transmission lines to enhance the safe and economic operation of the power grid [19-21]. In general, the objectives are reached by determining optimal control variables in the power system, including generator voltages, tap ratio of the transformers, and reactive power output of reactive power compensation device [22, 23]. For the sake of developing the full potential in reactive power regulation of RESs, the appropriate reactive power outputs of RESs should be globally controlled to coordinate with other control variables instead of local self-control [16, 24].

$\mathrm{RPO}$ is mathematically defined as a renowned nonlinear and nonconvex optimization problem involving discrete and continuous control variables, meanwhile, constrained by a series of equality and inequality constraints [25]. Note that all restrictions should be satisfied in the whole optimization process affirmatively. By far, remarkable research efforts have been done in RPO solution, among which the 
overwhelming majority employ conservative optimization methods such as linear programming [26], Newton method [27], dynamic programming [28], interior point method [29], and quadratic programming [30]. However, these conventional techniques always suffer several serious drawbacks in handling nondifferentiable functions and inequality constraints, as well as discrete variables, which are computationally intractable and may lead to loss of accuracy [31].

Thus far, numerous amounts of metaheuristic algorithms and their variant have been developed to solve such obstacles. Such intelligence optimization algorithms display tremendous potential in power system optimization thanks to their prominent merits of high flexibility, relatively simple structure, and rapid response, as well as the ability of handling nonlinear, large-scale, and multivariable optimization problems [32]. In particular, some groups are more popular to solve the RPO problem such as genetic algorithm (GA) $[33,34]$, particle swarm optimization (PSO) algorithm $[33,35]$, and moth-flame optimization (MFO) algorithm [36]. Particularly, literature [34] presents an improved GA for RPO, in which real and binary codes are employed, respectively, to address continuous and discrete variables. However, the computation time is not substantially lower than that of the original GA. Besides, the optimal reactive power dispatch is achieved by grey wolf optimizer (GWO) [37], where the best combination of control variables is found such that total power loss and total voltage deviation issues can be effectively solved [38]. Moreover, work [39] proposes a discrete binary PSO algorithm to address the overriding risk of voltage caused by wind power fluctuation. In general, most of them really lack unified control and planning for the reactive power output of RESs such that the potential in reactive power regulation of RESs has not been maximized. Moreover, most of the metaheuristic algorithms suffer from low searching efficiency and premature convergence drawbacks [40].

To address the abovementioned problems, a reliable fast atom search optimization (FASO) algorithm that derives from the original atom search optimization (ASO) algorithm [41] is performed to solve the intractable RPO problem. Compared to the original ASO algorithm, the effective searching mechanism that Euclidian distance ratio is selfadaptively updated according to the optimization results is introduced by FASO algorithm to realize a better balance between local exploitation and global exploration [42] and most importantly can accelerate convergence to high-quality solutions.

The rest of this paper is organized as follows: Section 2 establishes the reactive power optimization model of power grid considering high-penetration wind and solar energies, in which the total power loss and total voltage deviation are, respectively, treated as the single objective function to be minimized; Section 3 elaborates the basic principle of FASO algorithm and detailed design for RPO, where the control variables to be optimized are determined; Section 4 undertakes two case studies to validate the superiority and efficiency of the proposed algorithm for solving the RPO problem; eventually, several popular metaheuristic algorithms are executed along with the implementation of developed FASO algorithm to make a fair comparison; at last, conclusions are drawn in Section 5.

\section{Reactive Power Optimization Model of Power Grid with High-Penetration Wind and Solar Energies}

2.1. Reactive Power Regulation of Wind Generators. The configuration of doubly-fed induction generator (DFIG) connected to infinite power grid via two voltage source converters (VSCs) is illustrated in Figure 1, in which the mechanical power extracted from wind energy and active power injected into the power grid are directly related to wind speed [43].

Assume that the output of active power is accurately tracked by the maximum power point [44]. Based on the current wind speed, the active power can be calculated as follows [45]:

$$
P_{g}= \begin{cases}0, & \text { for } v_{w}<v_{w}^{\text {in }} \text { and } v_{w}>v_{w}^{\text {out }}, \\ P_{w}^{\text {base }} \frac{v_{w}-v_{w}^{\text {in }}}{v_{w}^{\text {base }}-v_{w}^{\text {in }}}, & \text { for } v_{w}^{\text {in }} \leq v_{w} \leq v_{w}^{\text {base }}, \\ P_{w}^{\text {base }}, & \text { for } v_{w}^{\text {base }} \leq v_{w} \leq v_{w}^{\text {out }},\end{cases}
$$

where $v_{w}, v_{w}^{\text {in }}$, and $v_{w}^{\text {out }}$ denote current, cut-in, and cut-out wind speed, respectively; $v_{w}^{\text {base }}$ means the rated wind speed; and $P_{w}^{\text {base }}$ is the rated output power of wind turbine.

With the help of stator-side VSC and grid-side VSC, wind turbines can generate active power over a wide range of rotational speeds around the synchronous speed at constant voltage and frequency. And the magnitude and direction of the active power that flows between the rotor and the grid are controlled. Furthermore, the instantaneous reactive power of wind generators can be controlled independently by the reactive power output of stator-side VSC and grid-side VSC, as follows [46]:

$$
\left\{\begin{array}{l}
Q_{g, \max }=Q_{s, \max }+Q_{c, \max } \\
Q_{g, \min }=Q_{s, \min }+Q_{c, \min }
\end{array}\right.
$$

where $Q_{g \text {, } m a x}$ and $Q_{g \text {, min }}$ stand for the maximum and minimum reactive power regulation capacity for wind turbine that injected into power grid, respectively; $Q_{s, \max }$ and $Q_{s, \text { min }}$ represent the maximum and minimum reactive power regulation capacity for stator-side VSC, respectively; and $Q_{c, \text { max }}$ and $Q_{c, \text { min }}$ are the maximum and minimum reactive power regulation capacity for grid-side VSC, respectively.

And then, the limits of the reactive power output of stator-side VSC are determined by the stator voltage, as well as maximum current specified on rotor-side and stator-side, as follows [47]: 


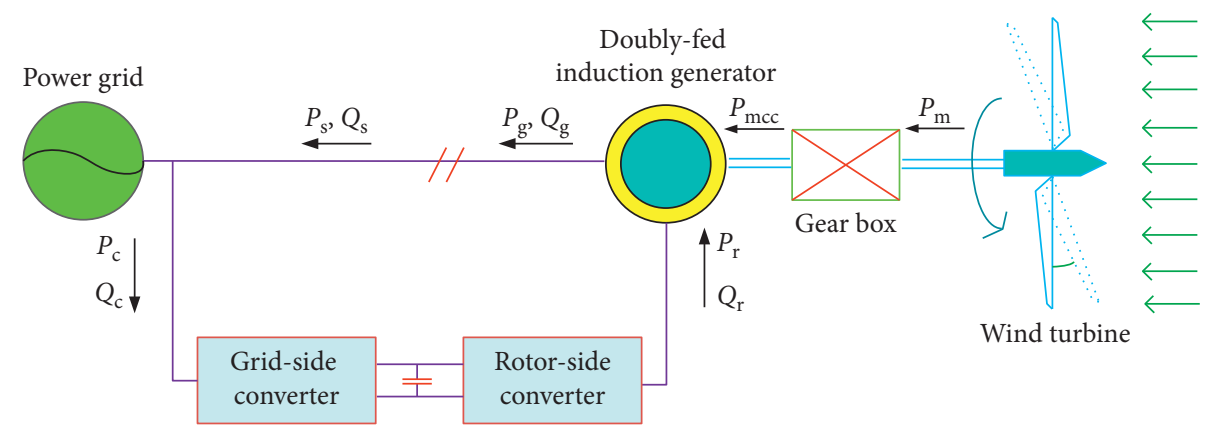

FIGURE 1: Energy conversion of doubly-fed induction generator.

$\left\{\begin{array}{l}Q_{s, \max }=\min \left\{Q_{s 1, \max }, Q_{s 2, \max }\right\}, \\ Q_{s, \min }=\max \left\{Q_{s 1, \min }, Q_{s 2, \min }\right\},\end{array}\right.$

$\left\{\begin{array}{l}Q_{s 1, \max }=-\frac{3 U_{s}^{2}}{2 \omega_{1} L_{s}}+\sqrt{\left(\frac{3 L_{m}}{2 L_{s}} U_{s} I_{r, \max }\right)^{2}-\left(\frac{P_{m}}{1-s}\right)^{2}}, \\ Q_{s 1, \min }=-\frac{3 U_{s}^{2}}{2 \omega_{1} L_{s}}-\sqrt{\left(\frac{3 L_{m}}{2 L_{s}} U_{s} I_{r, \max }\right)^{2}-\left(\frac{P_{m}}{1-s}\right)^{2}},\end{array}\right.$

$\left\{\begin{array}{l}Q_{s 2, \max }=\sqrt{\left(U_{s} I_{s, \max }\right)^{2}-\left(\frac{P_{m}}{1-s}\right)^{2}}, \\ Q_{s 2, \min }=-\sqrt{\left(U_{s} I_{s, \max }\right)^{2}-\left(\frac{P_{m}}{1-s}\right)^{2}},\end{array}\right.$

where $Q_{s 1 \text {, max }}$ and $Q_{s 1 \text {, min }}$ represent the lower and upper limits of reactive power regulation capacity for stator-side VSC under maximum current constraint on the rotor side, respectively; $Q_{s 2 \text {, max }}$ and $Q_{s 2 \text {, min }}$ mean the lower and upper of reactive power regulation capacity for stator-side VSC under maximum current constraint on the stator side, respectively; $L_{s}$ and $L_{m}$ stand for stator inductance and magnetizing inductance, respectively; $I_{r \text {, max }}$ and $I_{s, \text { max }}$ denote the maximum current specified on the rotor side and stator side, respectively; $U_{\mathrm{s}}$ refers to voltage virtual value of the stator; $s$ is slip ratio; and $\omega_{1}$ is the synchronous rotational speed.

Besides, the limits of reactive power output for grid-side VSC are mainly affected by the capacity of grid-side VSC, as follows [45]:

$$
\left\{\begin{array}{l}
Q_{c, \text { max }}=\sqrt{S_{c, \max }^{2}-\left(\frac{s P_{m}}{1-s}\right)^{2}}, \\
Q_{c, \text { min }}=-\sqrt{S_{c, \text { max }}^{2}-\left(\frac{s P_{m}}{1-s}\right)^{2}},
\end{array}\right.
$$

where $S_{c, \max }$ represents the capacity of grid-side VSC.
Hence, the limits of reactive power regulation capacity of each wind turbine at a certain wind speed can be determined and then the whole wind farm [46].

2.2. Reactive Power Regulation of PV Generators. The active power output of photovoltaic (PV) stations depends mainly upon the solar irradiation and temperature. Assuming that the output power is regulated via the maximum power point tracking (MPPT) control; accordingly, the output of active power can be expressed as follows $[47,48]$ :

$$
P_{\mathrm{pv}}=P_{\mathrm{pv}}^{\mathrm{base}}\left(1+\alpha_{\mathrm{pv}} \cdot\left(T-T_{\mathrm{ref}}\right)\right) \cdot \frac{S_{\mathrm{pv}}}{1000},
$$

where $P_{\mathrm{pv}}^{\text {base }}$ denotes the rated generated output of PV stations; $\alpha_{\mathrm{pv}}$ means temperature-power conversion factor; $T$ and $T_{\text {ref }}$ represent current ambient temperature and reference temperature, respectively; and $S_{\mathrm{pv}}$ refers to current solar irradiation.

Here, the limits of reactive power regulation capacity for PV stations largely rely on the current active power output and the capacity of PV inverter, as follows:

$$
\left\{\begin{array}{l}
Q_{\mathrm{pv}, \max }=\sqrt{\left(S_{\mathrm{pv}}\right)^{2}-\left(P_{\mathrm{pv}}\right)^{2}}, \\
Q_{\mathrm{pv}, \min }=-\sqrt{\left(S_{\mathrm{pv}}\right)^{2}-\left(P_{\mathrm{pv}}\right)^{2}},
\end{array}\right.
$$

where $Q_{\mathrm{pv}, \max }$ and $Q_{\mathrm{pv} \text {,min }}$ represent the lower and upper of reactive power regulation capacity for PV stations, respectively; $S_{\mathrm{pv}}$ stands for the capacity of PV inverter.

2.3. Reactive Power Optimization Model. The RPO model constructed in this paper aims to minimize the total power loss in all transmission lines and total voltage deviation of all nodes, as follows:

$$
\begin{aligned}
& \min f(x) \\
& \left\{\begin{array}{l}
f(x)=P_{\text {loss }}=\sum_{i, j \in N_{L}} g_{i j}\left[V_{i}^{2}+V_{j}^{2}-2 V_{i} V_{j} \cos \theta_{i j}\right] \\
f(x)=V_{d}=\sum_{j \in N_{i}}\left(V_{j}-V_{j}^{*}\right)^{2},
\end{array}\right.
\end{aligned}
$$

where $P_{\text {loss }}$ means total power loss of the power grid; $V_{d}$ denotes total voltage deviation of all nodes, which refers to 
per-unit value; $V_{i}, V_{j}$, and $\theta_{i j f}$ represent the voltage amplitude of node $i$ and node $j$, and the phase angle difference between them, respectively; $g_{i j}$ refers to the admittance between node $i$ and node $j ; N_{i}$ and $N_{L}$ stand for the set of all nodes and the set of all branches; and $V_{j}{ }^{*}$ is the rated voltage of node $j$.

In terms of the considered optimization problem, the objective functions are subjected to several equality and inequality constraints, in which all constraints to be considered are described as follows:

(1) Power flow constraints

$$
\begin{cases}P_{G i}-P_{D i}-V_{i} \sum_{j \in N_{i}} V_{j}\left(g_{i j} \cos \theta_{i j}+b_{i j} \sin \theta_{i j}\right)=0, & i \in N_{0}, \\ Q_{G i}-Q_{D i}-V_{i} \sum_{j \in N_{i}} V_{j}\left(g_{i j} \sin \theta_{i j}-b_{i j} \cos \theta_{i j}\right)=0, & i \in N_{P Q},\end{cases}
$$

where $P_{\mathrm{G} i}$ and $Q_{\mathrm{G} i}$ are active and reactive power generation of node $i$, respectively; $P_{\mathrm{D} i}$ and $Q_{\mathrm{D} i}$ represent active and reactive power load, respectively; $b_{i j}$ mean the susceptance between node $i$ and node $j ; N_{0}$ denotes the set of nodes except for slack bus; and $N_{\mathrm{PQ}}$ is the set of PQ buses.

(2) Generator constraints

$$
\left\{\begin{array}{l}
P_{G b}^{\min } \leq P_{G b} \leq P_{G b}^{\max }, \\
Q_{G i}^{\min } \leq Q_{G i} \leq Q_{G i}^{\max }, \quad i \in N_{G}, \\
V_{G i}^{\min } \leq V_{G i} \leq V_{G i}^{\max }, \quad i \in N_{G},
\end{array}\right.
$$

where $P_{\mathrm{Gb}}$ denotes active power generation of slack bus; $P_{\mathrm{Gb}}{ }^{\mathrm{min}}$ and $P_{\mathrm{Gb}}{ }^{\max }$ represent the maximum and minimum active power generation regulation at slack bus, respectively; $Q_{\mathrm{G} i}{ }^{\min }$ and $Q_{\mathrm{G} i}{ }^{\max }$ denote the maximum and minimum reactive power regulation of generator; $V_{\mathrm{G} i}{ }^{\min }$ and $V_{\mathrm{G} i}{ }^{\max }$ stand for the maximum and minimum output voltage of generators; and $N_{\mathrm{G}}$ is the number of all generators.

(3) Constraints of reactive power compensation device and transformer tap

$$
\left\{\begin{array}{l}
Q_{C i}^{\min } \leq Q_{C i} \leq Q_{C i}^{\max }, \quad i \in N_{C}, \\
T_{h}^{\min } \leq T_{h} \leq T_{h}^{\max }, \quad h \in N_{T},
\end{array}\right.
$$

where $Q_{\mathrm{C} i}{ }^{\min }$ and $Q_{\mathrm{C} i}{ }^{\max }$ stand for the maximum and minimum capacity of the $i$-th reactive power compensation device, respectively; $T_{h}{ }^{\min }$ and $T_{h}{ }^{\max }$ represent the lower and upper limits of the $h$-th transformer tap; $N_{\mathrm{C}}$ is the number of reactive power compensation devices; and $N_{\mathrm{T}}$ is the number of transformer taps.

(4) Security constraints

$$
\left\{\begin{array}{l}
V_{i}^{\min } \leq V_{i} \leq V_{i}^{\max }, \quad i \in N_{P Q}, \\
\left|S_{l}\right| \leq S_{l}^{\max }, \quad l \in N_{L},
\end{array}\right.
$$

where $V_{i}^{\text {min }}$ and $V_{i}^{\max }$ mean the lower and upper limits of voltage of node $i$, respectively; $S_{l}$ and $S_{l}^{\max }$ are apparent power and transmission power limit of line $l$, respectively; and $N_{L}$ is the number of lines.

\section{Design of Fast Atom Search Optimization Algorithm}

The proposed FASO algorithm is developed from the original ASO algorithm, which is also inspired by the molecular dynamics in nature, where each atom in the populations will interact with others by means of the interaction forces resulting from Lennard-Jones (L-J) potential and the geometric constraints between them [40]. The interactions among atoms contain two options, i.e., repulsion and attraction. The farmer is used to avoid overcrowding of atoms while the latter is to bind atoms together. In particular, the repulsion brings a wider global exploration capability while the attraction ensures a deeper local exploitation ability. Note that the repulsion will gradually weaken and the attraction will increasingly strengthen for seeking the globally optimal solutions in the iteration process. Besides, geometric constraint also leads to a deeper local exploitation due to its ability to propel all atoms; especially, worse atoms approximate the current optimal solutions.

3.1. Inspiration. In FASO, the L-J potential essentially characterizes the potential energy between two interactive atoms, which is also seen as the power of atomic motion. The potential energy on the $i$ th atom imposed by the $j$ th atom can be rewritten as follows:

$$
U\left(r_{i j}\right)=4 \varepsilon\left[\left(\frac{\sigma}{r_{i j}}\right)^{12}-\left(\frac{\sigma}{r_{i j}}\right)^{6}\right],
$$

where $\varepsilon$ and $\sigma$ denote the depth of the potential well and the length scale, respectively, and $r_{i j}$ denotes Euclidian distance between the $j$ th and the $i$ th atoms, $r_{i j}=\left\|\mathbf{x}_{j}-\mathbf{x}_{i}\right\|$.

Then, the interaction forces on the $i$ th atom imposed by the $j$ th atom can be expressed as follows [40]:

$$
\begin{aligned}
F_{i j}=-\nabla U\left(r_{i j}\right) & =\frac{24 \varepsilon}{\sigma^{2}}\left[2\left(\frac{\sigma}{r_{i j}}\right)^{14}-\left(\frac{\sigma}{r_{i j}}\right)^{8}\right] \mathbf{r}_{i j}, \\
F_{i j}^{\prime} & =\frac{24 \varepsilon}{\sigma}\left[2\left(\frac{\sigma}{r_{i j}}\right)^{13}-\left(\frac{\sigma}{r_{i j}}\right)^{7}\right] .
\end{aligned}
$$

As demonstrated in Figure 2, the potential energy largely depends on the relative distance among atoms. It is easy to note that the whole potential energy area is fallen into repulsion region and attraction region, in which the equilibrium between two regions can be achieved when $(\sigma / r)=1.12$. Note that the potential energy will dramatically decrease as the Euclidean distance between two atoms increases when two atoms repel each other. In addition, the potential energy will slowly decrease to be zero with the increase of Euclidian distance when two atoms attract each other. Crucially, more positive attraction and less negative repulsion are required to be assured as iterations increase. 


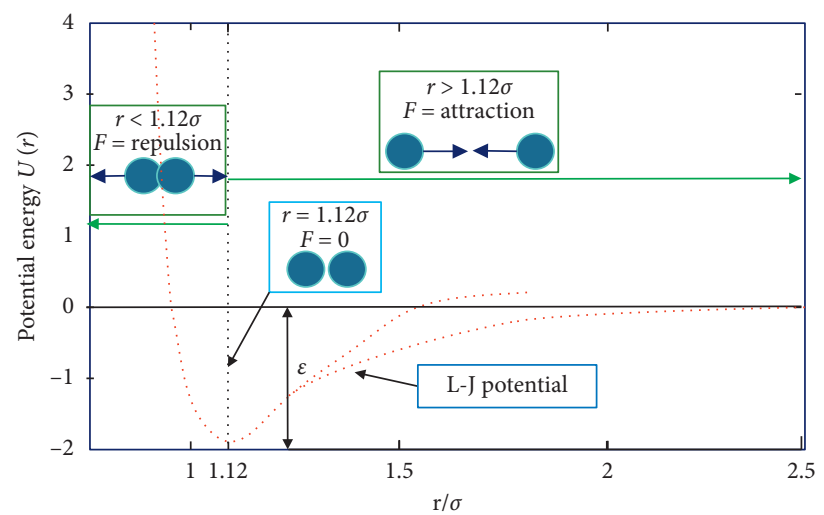

Figure 2: Potential energy of atoms under different input parameters.

Hence, the interaction forces can be calculated by a modified equation, as follows [41]:

$$
F_{i j}^{\prime}(k)=-\eta(k)\left[2\left(h_{i j}(k)\right)^{13}-\left(h_{i j}(k)\right)^{7}\right],
$$

where $\eta(k)$ denotes the depth function at the $k$ th iteration and $h_{i j}(k)$ means distance ratio between the $j$ th and the $i$ th atoms, which can be updated by the following equation [41]:

$$
\begin{gathered}
\eta(k)=\alpha\left(1-\frac{k-1}{k_{\max }}\right)^{3} e^{-\left(20 k / k_{\max }\right),} \\
h_{i j}(k)= \begin{cases}h_{\min }, & \text { if } \frac{r_{i j}(k)}{\sigma(k)}<h_{\min }, \\
\frac{r_{i j}(k)}{\sigma(k)}, & \text { if } h_{\min } \leq \frac{r_{i j}(k)}{\sigma(k)} \leq h_{\max }, \\
h_{\max }, & \text { if } \frac{r_{i j}(k)}{\sigma(k)}>h_{\max }, \\
\sigma(k)= & \mathbf{r}_{i j}(k), \frac{\sum_{l \in \mathbf{X}_{\text {best }}} \mathbf{r}_{i l}(k)}{L(k)} \|_{2},\end{cases}
\end{gathered}
$$

where $\alpha$ denotes depth weight, $h_{\max }$ and $h_{\min }$ mean the upper and lower limits of distance ratios, and $\mathbf{X}_{\text {best }}$ represents the subset of the best $L$ atoms.

As illustrated in Figure 3, $F^{\prime}$ is directly related to the input variables $\eta$ and $h$. Therefore, the interaction force could be also controlled by the limits of $h$, in which the upper limit of $h$ is set to be 1.24 like the original ASO algorithm. Moreover, the lower limit of $h$ is determined to be 1.1 or 1.2, which is one improvement of FASO. In FASO, atoms can perform a wider global exploration if a better solution that compared with the previous optimal solution cannot be found, and consequently, a smaller lower limit of $h$ is required. On the contrary, a deeper local exploitation is needed if the best solution has been updated. The lower limit of $h$ is expressed as follows:

$$
\begin{aligned}
& h_{\min }(k)= \begin{cases}1.1+w(k), & \text { If Fit }\left(x_{\text {best }}(k)\right) \leq \operatorname{Fit}\left(x_{\text {best }}^{p}\right), \\
1.2, & \text { otherwise, }\end{cases} \\
& w(k)=0.1 \cdot \sin \left(\frac{\pi}{2} \cdot \frac{k}{k_{\max }}\right),
\end{aligned}
$$

where Fit refers to the fitness function; $\mathbf{x}_{\text {best }}(k)$ and $\mathbf{x}_{\text {best }}^{p}$ mean the best solution obtained at the $k$ th iteration and the previous best solution, respectively; and $w(k)$ is a function that can drive the FASO algorithm drift from exploration to exploitation [43].

Moreover, variable $L$ also has a great impact on the interaction force. In the ASO algorithm, $L$ atoms with better fitness value are treated as the neighbors of a certain atom, 


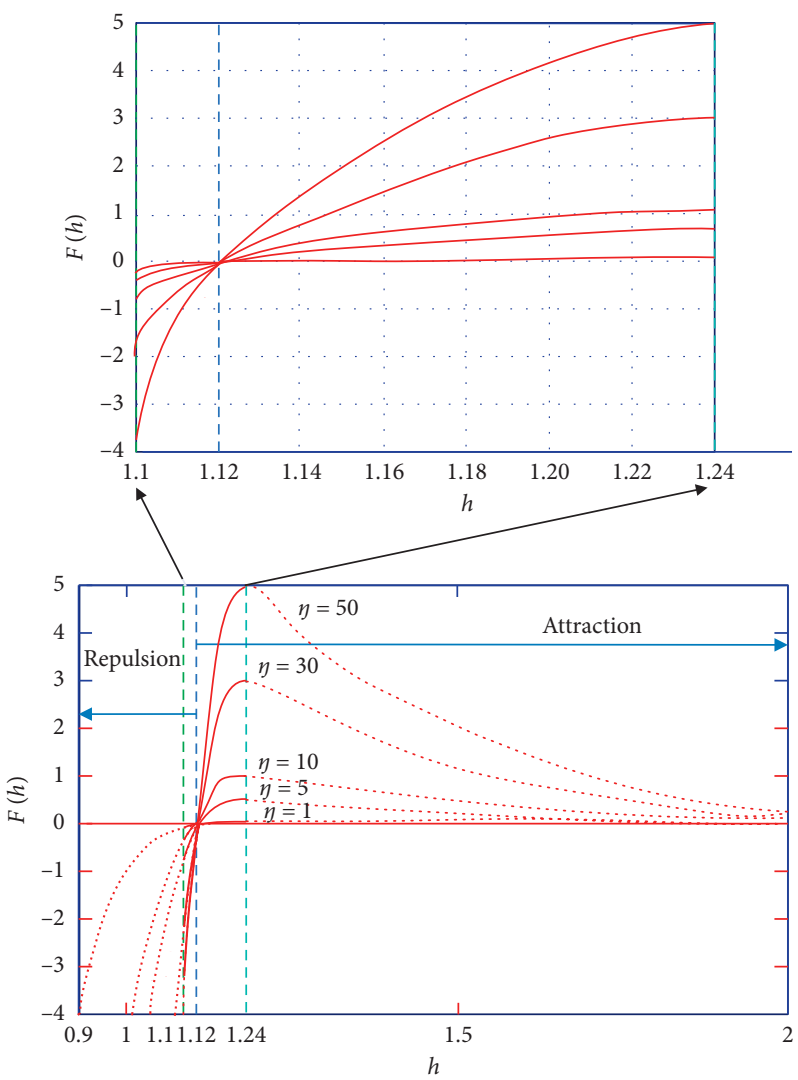

FiguRe 3: Function behaviours of $F^{\prime}$ under different input parameters.

and thus which variable $L$ denotes the number of atoms that are selected to interact with such atom. In the first stage of iterations, larger $L$, i.e., as many atoms as possible, the $L$ neighbors of such atom are needed to obtain the high exploration ability in the search space and thus can well avoid being trapped into the local optimal. On the contrary, each atom needs to interact with as few atoms with better fitness value as its $L$ neighbors at the end of iterations are needed to rapidly obtain high-quality solution. In general, FASO should implement a wide global exploration when it cannot find a better solution compared with the previous best solution, while a deep local exploitation is required when it can find a better solution. Hence, as a function of time, $L$ gradually decreases with the lapse of iterations. Besides, in this paper, the number of neighboring atoms is selected as 2 when it finds a better solution compared with the previous best solution. Hence, the FASO algorithm develops another improvement compared with the ASO algorithm [41], as follows:

$$
L(k)=\left\{\begin{array}{l}
n-(n-2) \times \sqrt{\frac{k}{k_{\max }}}, \quad \text { If Fit }\left(\mathbf{x}_{\text {best }}(k)\right) \leq \operatorname{Fit}\left(\mathbf{x}_{\text {best }}^{p}\right), \\
2, \quad \text { otherwise, }
\end{array}\right.
$$

where $n$ is the population size.
Hence, the total interaction force that acted on the $i$ th atom from the $j$ th atoms can be given by

$$
F_{i}(k)=\sum_{j=1, j \neq i}^{L(k)} F_{i j}(k) .
$$

3.2. Geometric Constraint. The geometric constraint [49] plays a crucial role in atomic searching motion to keep the polyatomic molecule structure of FASO. Assume that each atom has a covalent bond with the best atom. Accordingly, the geometric constraint force of the $i$ th atom from the best atom can be expressed as follows [37]:

$$
\begin{aligned}
\theta_{i}(k) & =\left[\left|\mathbf{x}_{i}(k)-\mathbf{x}_{\text {best }}^{p}(k)\right|^{2}-b_{i}^{2}\right], \\
G_{i}(k) & =-\lambda(k) \nabla \theta_{i}(k)=-2 \lambda(k)\left(\mathbf{x}_{i}(k)-\mathbf{x}_{\text {best }}^{p}(k)\right), \\
\lambda(k) & =\beta e^{-\left(20 k / k_{\max }\right),}
\end{aligned}
$$

where $\theta_{i}$ denotes the geometric constraint of the $i$ th atom; $G_{i}$ represents the constraint force of the $i$ th atom; and $\lambda$ and $\beta$ mean the Lagrangian multiplier and multiplier weight, respectively.

3.3. Atomic Searching Motion. The interaction forces and geometric constraints have a joint influence on the atomic motion. Each atom moves to a new positive following 
Newton's second law, in which the acceleration of each atom is given by [37]

$$
\begin{aligned}
M_{i}(k) & =e^{\left(\left(\operatorname{Fit}\left(\mathbf{x}_{\text {best }}(k)\right)-\operatorname{Fit}\left(\mathbf{x}_{i}(k)\right)\right) /\left(\operatorname{Fit}\left(\mathbf{x}_{\text {worst }}(k)\right)-\operatorname{Fit}\left(\mathbf{x}_{\text {best }}(k)\right)\right)\right)}, \\
m_{i}(k) & =\frac{M_{i}(k)}{\sum_{j=1}^{n} M_{j}(k)}, \\
\mathbf{a}_{i}(k) & =\frac{F_{i}(k)+G_{i}(k)}{m_{i}(k)}, \quad i=1,2, \ldots, n,
\end{aligned}
$$

where $\mathbf{x}_{\text {worst }}(k)$ is the worst solution required at the $k$ th iteration.

It is similar to PSO algorithm [50], and the velocity and position of each atom can be updated as follows [37]:

$$
\begin{gathered}
\mathbf{v}_{i}(k+1)=\mathbf{c} \cdot \mathbf{v}_{i}(k)+\mathbf{a}_{i}(k), \\
\mathbf{x}_{i}(k+1)=\mathbf{x}_{i}(k)+\mathbf{v}_{i}(k+1),
\end{gathered}
$$

where $\mathbf{c}$ denotes a random vector with the same dimensions of $\mathbf{x}_{i}$ in the range of $[0,1]$.

\subsection{The Implementation of FASO Algorithm}

\section{(1) Controllable variables}

RPO of power grid with the participation of wind and solar energies is regarded as a multiconstrained nonlinear and nonconvex optimization problem, which contains both continuous variables and discrete variables, i.e., terminal voltage of generators, the capacity of static VAR compensator (SVC), reactive power output of wind and solar energies, and the tap ratio of transformers in the substations [14]. Continuous variables can converge to the optimal value in the iteration process while the optimal value of discrete variables is needed to be rounded in the continuous space [51].

(2) Fitness function

The fitness function of FASO depends largely on the objectives and constraints of the RPO model, which can be designed as follows:

$$
\operatorname{Fit}(\vec{C})=\mu_{1} \frac{P_{\text {loss }}}{P_{\text {base }}}+\left(1-\mu_{1}\right) V_{d}+\eta q \text {, }
$$

where $\eta$ denotes penalty coefficient, which is generally set to be a biggish positive constant and $q$ represents the number of constraints that are not satisfied.

(3) Overall optimizing process

In the end, the overall optimizing process of FASObased RPO is elaborated in Figure 4.

\section{Case Studies}

The extended IEEE 9-bus and extended IEEE 39-bus test systems integrated with PV and wind generators are utilized in the simulation analysis of RPO for verifying the feasibility of the proposed algorithm. Meanwhile, the effects of weather conditions on RPO results also are discussed. All simulations are programmed in the personal computer on the Matlab $2017 \mathrm{~b}$ and Matpower 7.0b1. Optimization performance of FASO algorithm is compared to that of GA [34], PSO algorithm [39], GWO algorithm [37], and ASO [41]. Assume that the wind speed of wind farms and the solar irradiation of PV stations are maintained constant, respectively which are set to be $10 \mathrm{~m} / \mathrm{s}$ and $800 \mathrm{~W} / \mathrm{m}^{2}$. The control variables of RPO contain terminal voltages of conventional coal-fired units, SVC capacity, reactive power output of wind and solar energies, and the tap ratio of the transformers in the substations, of which the first three are continuous, while the last one is discrete. The ranges of these control variables are tabulated in Table 1. Meanwhile, the number of control variables applied in the extended IEEE 9 and IEEE 39-bus systems is given in Table 2.

4.1. Simulation Analysis of IEEE 9-Bus Test System. In the first case, the RPO is conducted in the extended IEEE 9-bus system, where the topology of the distribution network is demonstrated in Figure 5. Obviously, bus 1 represents the slack bus whose voltage magnitude is assumed to be constant, wind farm is connected to bus 7 and PV station is connected to bus 9, as well as SVC is connected to bus 4. As for the extended IEEE 9-bus test system, the base capacity of the system is $100 \mathrm{MW}$, the installed capacities of PV stations and wind farm are, respectively, $20 \mathrm{MW}$ and $10 \mathrm{MW}$. For the sake of a relatively fair comparison, the population size of the proposed algorithm and other algorithms all are set to be 20, and the maximum iteration is set to be 100 . Some specific parameters of all comparison algorithms are set to the default values. If the parameters are not chosen properly, the convergence time will be too long or the local optimum will be trapped. It is worth mentioning that the key parameters in the FASO algorithm, i.e., the depth weight $\alpha$, the multiplier weight $\lambda$, and the limits of distance ratios $h$, are determined to be 80,1 , and 1.1(1.2)/1.24 by four different benchmark functions, namely, the Sphere, Rosenbrock, Ackley, and Griewank functions, respectively $[11,41]$.

This paper performs the single objective optimization, in which total power loss of all transmission lines and total voltage deviation of all nodes are, respectively, regarded as the objective functions to determine the optimal scheme of RPO. Figures 6(a) and 6(b), respectively, provide the convergence curves of total power loss and total voltage deviation obtained by different algorithms in the extended IEEE 9-bus test system. Simulation results explicitly validate that FASO algorithm can acquire the high-quality solution most effectively and efficiently among all the algorithms. In contrast, PSO reveals the slowest convergence rate compared to that of other algorithms. Moreover, Figures 7(a) and 7(b), respectively, give the box-and-whisker diagrams of RPO results acquired by different algorithms, which indicate that FASO algorithm can distribute within the smallest range with minimal lower and upper bounds among all algorithms. It verifies that FASO algorithm owns the highest convergence stability and searching ability. 


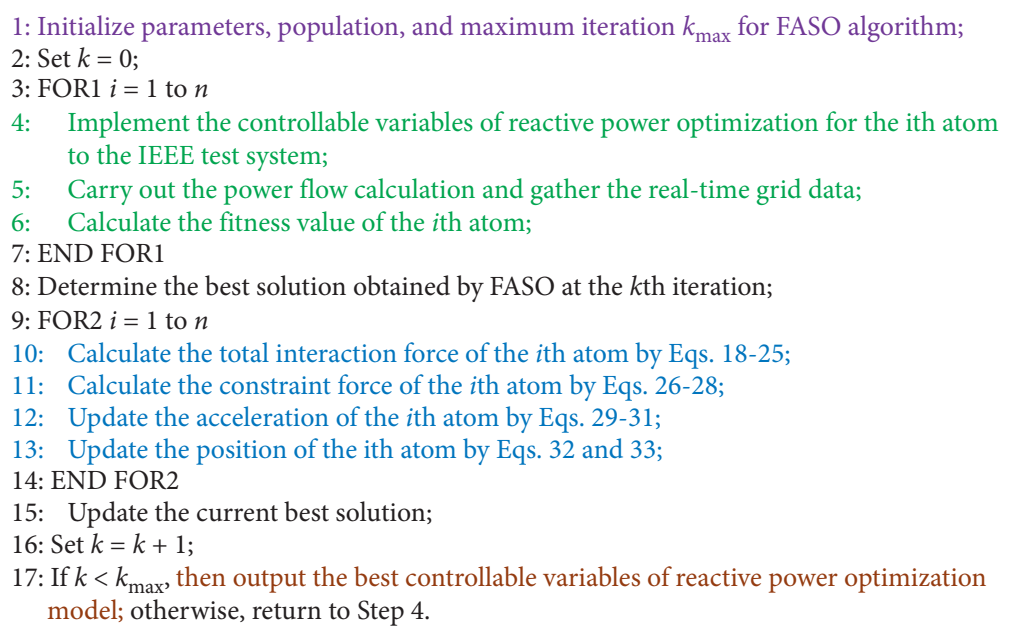

FIgURE 4: Overall optimizing process of FASO for RPO problem.

TABLE 1: The ranges of control variables applied in the extended IEEE 9 and IEEE 39-bus systems.

\begin{tabular}{lccccc}
\hline $\begin{array}{l}\text { Test } \\
\text { systems }\end{array}$ & $\begin{array}{c}\text { Terminal voltage of } \\
\text { generators (p.u.) }\end{array}$ & $\begin{array}{c}\text { Capacity of SVC } \\
(\text { Mvar })\end{array}$ & $\begin{array}{c}\text { Reactive power output of } \\
\text { wind energy (Mvar) }\end{array}$ & $\begin{array}{c}\text { Reactive power output of } \\
\text { solar energy (Mvar) }\end{array}$ & $\begin{array}{c}\text { Tap ratio of the } \\
\text { transformers }\end{array}$ \\
\hline $\begin{array}{l}\text { IEEE 9- } \\
\text { bus }\end{array}$ & {$[1,1.05]$} & {$[1,5]$} & {$[-7.62,9.09]$} & {$[-7.55,7.55]$} & - \\
$\begin{array}{l}\text { IEEE 39- } \\
\text { bus }\end{array}$ & {$[1,1.07]$} & - & {$[-7.62,9.09]$} & {$[-7.55,7.55]$} & {$[0.96,0.97$,} \\
\hline
\end{tabular}

TABLE 2: The number of control variables applied in the extended IEEE 9 and IEEE 39-bus systems.

\begin{tabular}{|c|c|c|c|c|c|c|}
\hline $\begin{array}{l}\text { Test } \\
\text { systems }\end{array}$ & $\begin{array}{l}\text { Terminal voltage of } \\
\text { generators }\end{array}$ & $\begin{array}{l}\text { Capacity of } \\
\text { SVC }\end{array}$ & $\begin{array}{l}\text { Reactive power output of } \\
\text { wind energy }\end{array}$ & $\begin{array}{l}\text { Reactive power output of } \\
\text { solar energy }\end{array}$ & $\begin{array}{l}\text { Tap ratio of the } \\
\text { transformers }\end{array}$ & Total \\
\hline $\begin{array}{l}\text { IEEE 9- } \\
\text { bus }\end{array}$ & 3 & 1 & $\mathrm{C}_{\mathrm{C}}$ & $\mathrm{C}_{\mathrm{C}}$ & - & 6 \\
\hline $\begin{array}{l}\text { IEEE 39- } \\
\text { bus }\end{array}$ & 10 & - & 5 & 5 & 12 & 32 \\
\hline
\end{tabular}

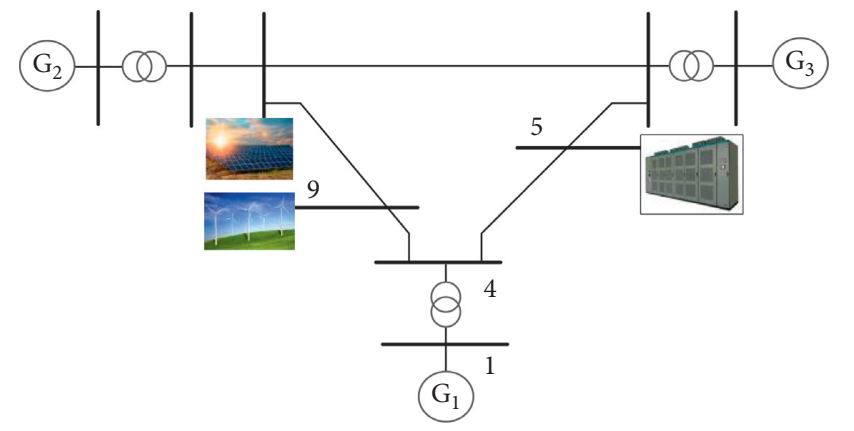

(G) : Thermal power plant

$$
\begin{aligned}
& \text { : Static VAR compensator } \\
& \text { (8) :Transformer }
\end{aligned}
$$

: Photovoltaic plant

FIGURE 5: Network topology for IEEE 9-bus system.

For the sake of analyzing the impact of wind speed and solar irradiance on the RPO in the extended IEEE 9-bus system, the distributions of RPO results acquired by the
FASO algorithm under different weather conditions are shown in Figure 8. It can be easily found that power loss gradually increases with the increase of wind speed while gradually decreases as solar irradiance increases. Such results manifest that the increase of power loss does not entirely depend on the active power output of wind and solar energies, of which other effects include the locations of wind and PV generators installed and operating condition of power grid as well [31]. In addition, the total voltage deviation gradually decreases owing to the reduction of the active power output of wind and solar energies and accordingly the increase of reactive power regulation capacity when the wind speed or solar irradiance is significantly reduced.

4.2. Simulation Analysis of IEEE 39-Bus Test System. In the second case, the RPO is conducted in the extended IEEE 39bus system, where the topology of the distribution network is demonstrated in Figure 9. Note that the slack bus is located in bus 1, five PV generators are, respectively, installed buses 


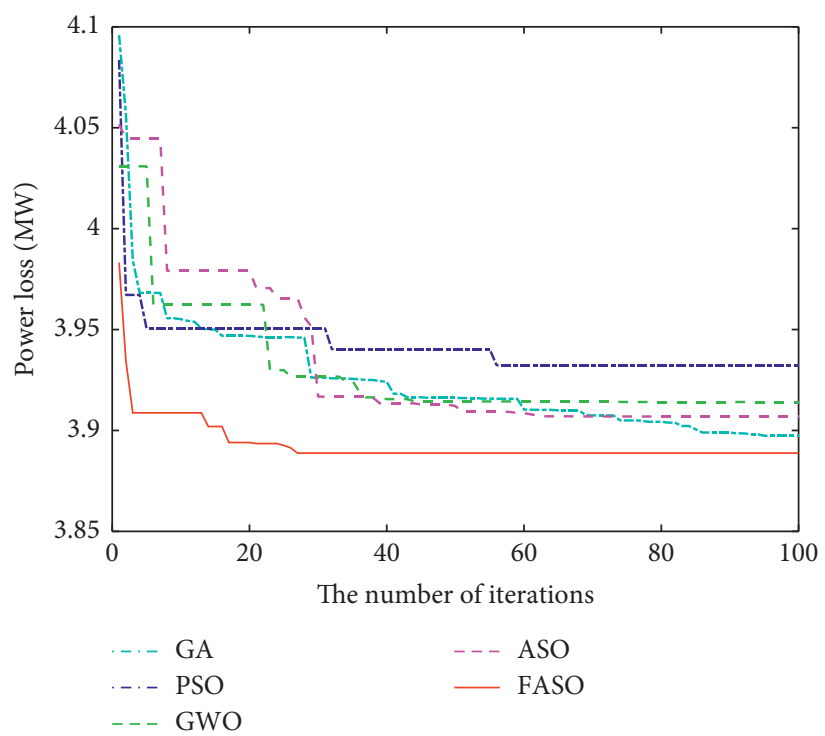

(a)

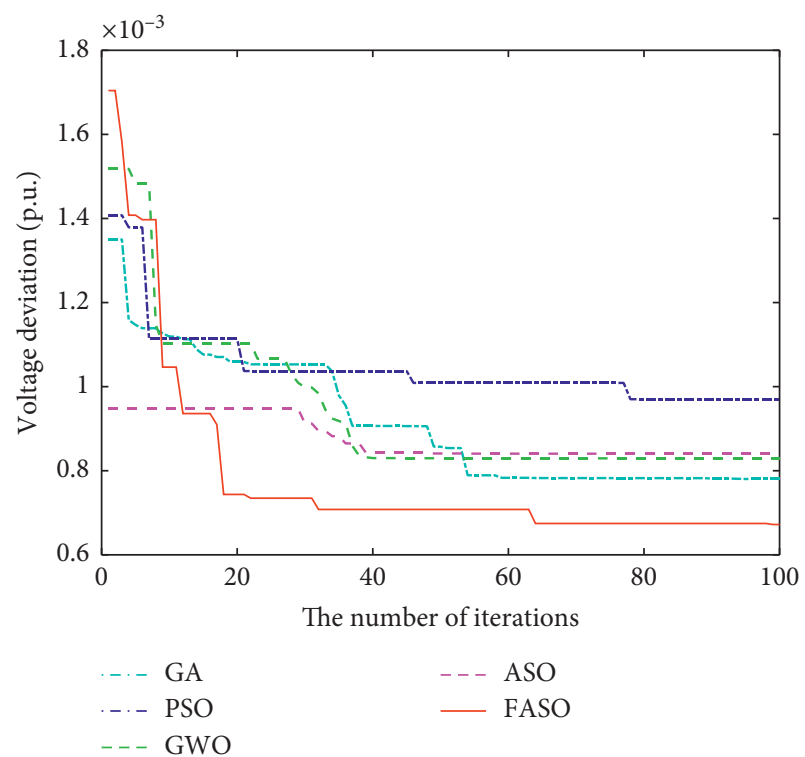

(b)

FIgURE 6: Convergence curves of RPO results obtained by different algorithms in the extended IEEE 9-bus system. (a) Power loss; (b) voltage deviation.

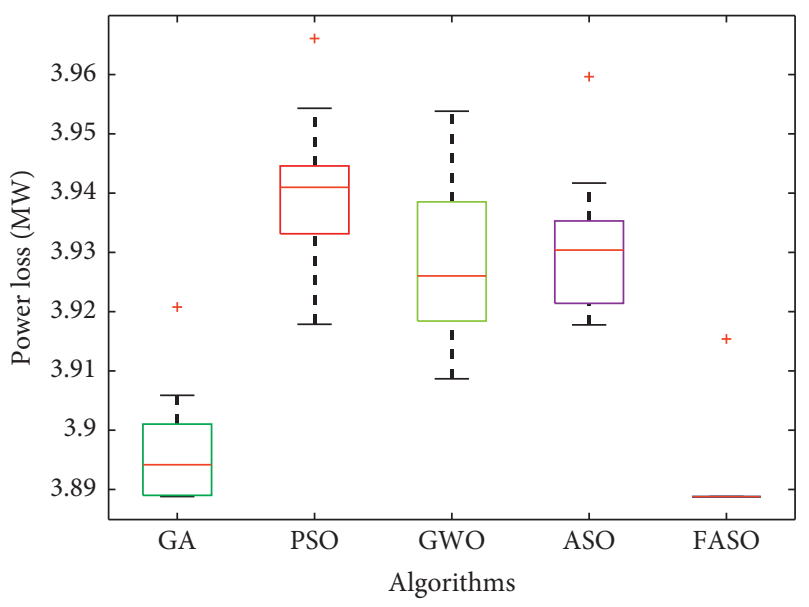

(a)

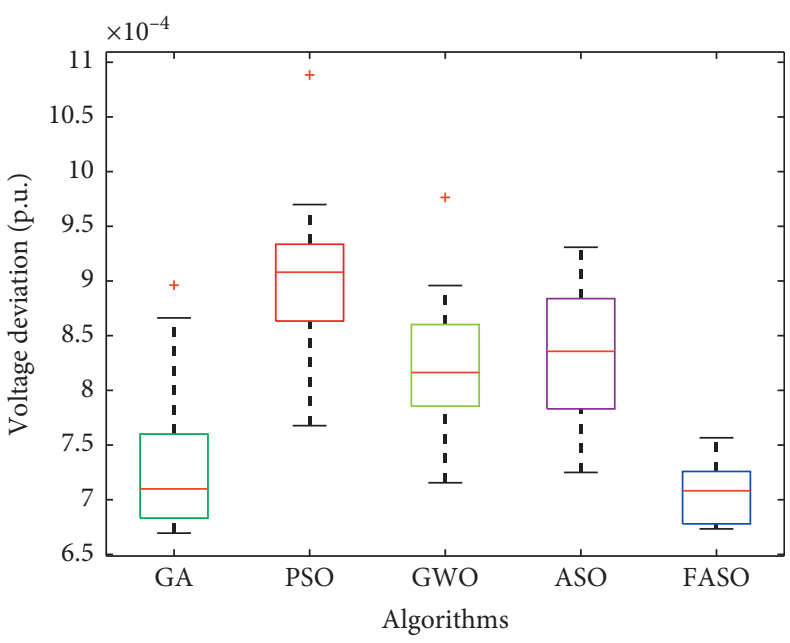

(b)

Figure 7: Box-and-whisker plots of RPO results obtained by different algorithms in 20 runs in the extended IEEE 9-bus system. (a) Power loss; (b) voltage deviation.

$1,4,6,7$, and 20, and five wind generators are, respectively, installed buses $21,23,25,27$, and 28 . The base capacity of the system is $100 \mathrm{MW}$, and the installed capacities of PV stations and wind farms are, respectively, $30 \mathrm{MW}$ and $20 \mathrm{MW}$. In addition, the population size of all algorithms is set to be 40 , and the maximum iteration is set to be 100 .

In the extended IEEE 39-bus test system, the convergence curves and the box-and-whisker diagrams of RPO results produced by different algorithms are illustrated in Figures 10 and 11, respectively. Obviously, optimization performances of the FASO algorithm such as convergence stability, convergence speed, and searching ability noticeably improve with the increase of system scale and the number of control variables. It indicates that FASO algorithm is also applicable to large-scale networks for RPO solution.

To investigate further, the distributions of total power loss and total voltage deviation under different weather conditions acquired by the FASO algorithm in the extended IEEE 39-bus system are illustrated in Figure 12. It can be concluded that power loss and voltage deviation are subject to some other factors rather than only the power output of renewable energies. For optimal operation in security and 


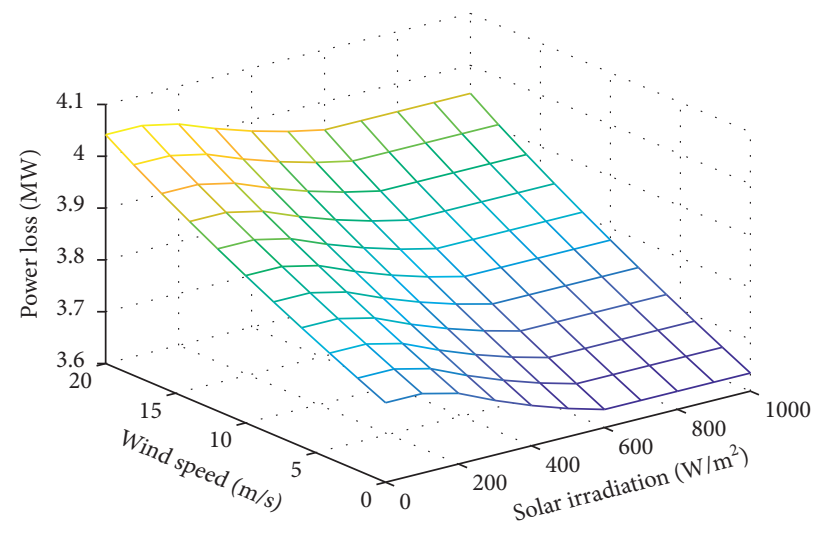

(a)

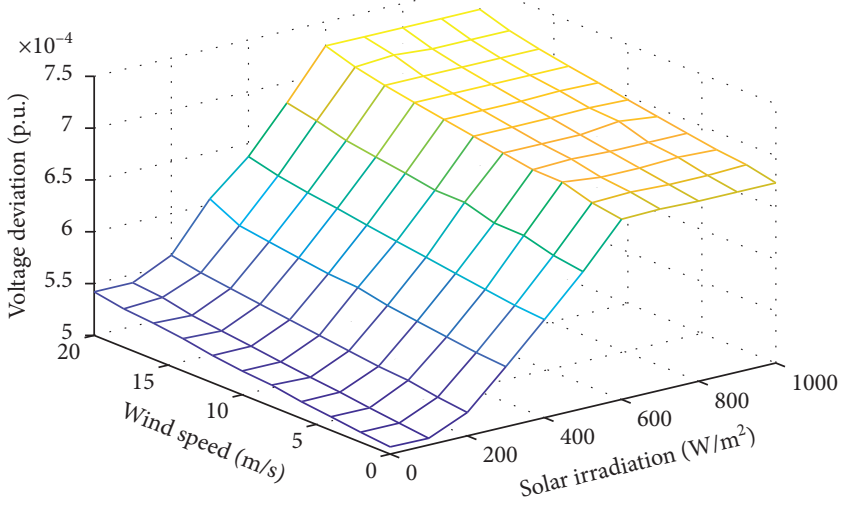

(b)

FIGURE 8: Distributions of RPO results obtained by FASO under different weather conditions of IEEE 9-bus system. (a) Power loss; (b) voltage deviation.

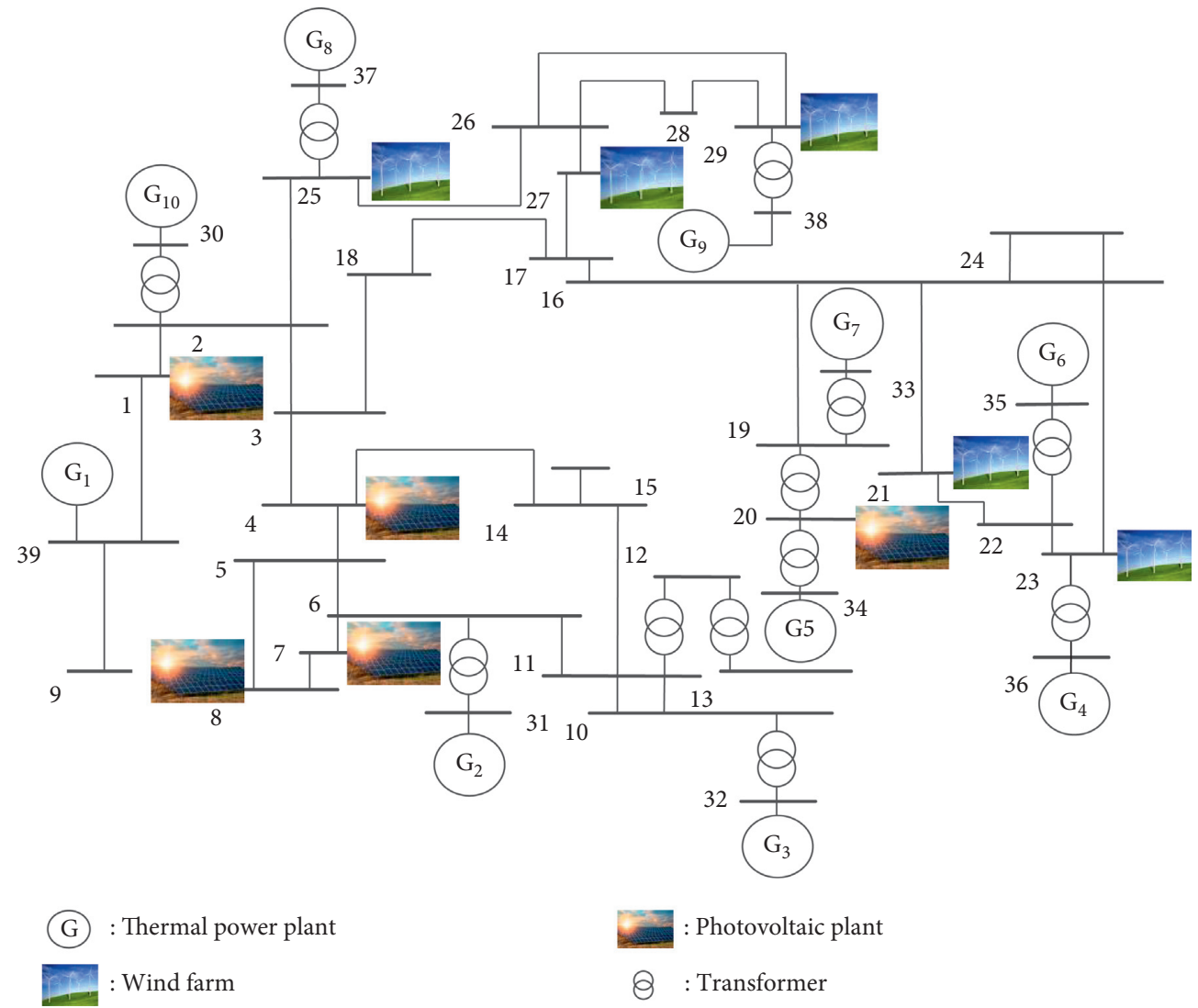

FIgURE 9: Network topology for IEEE 39-bus system. 


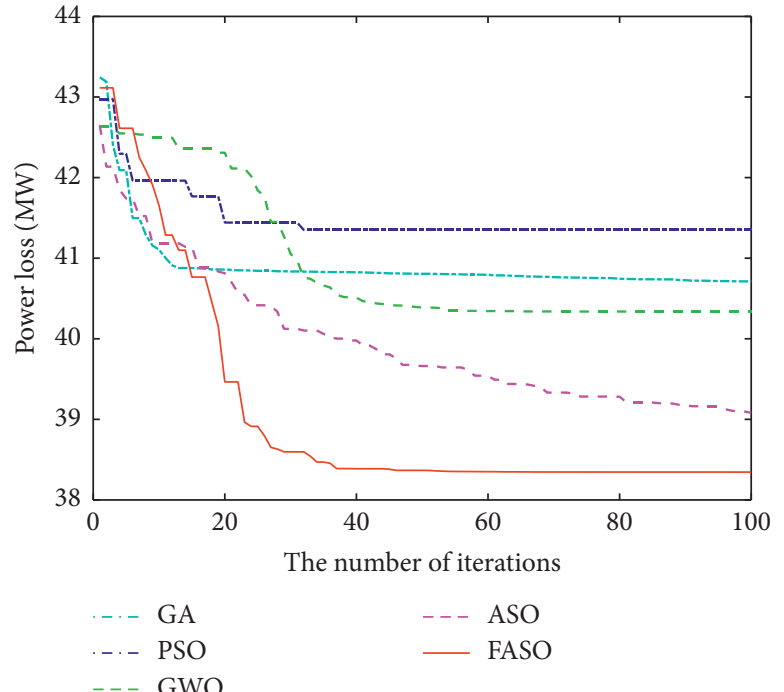

(a)

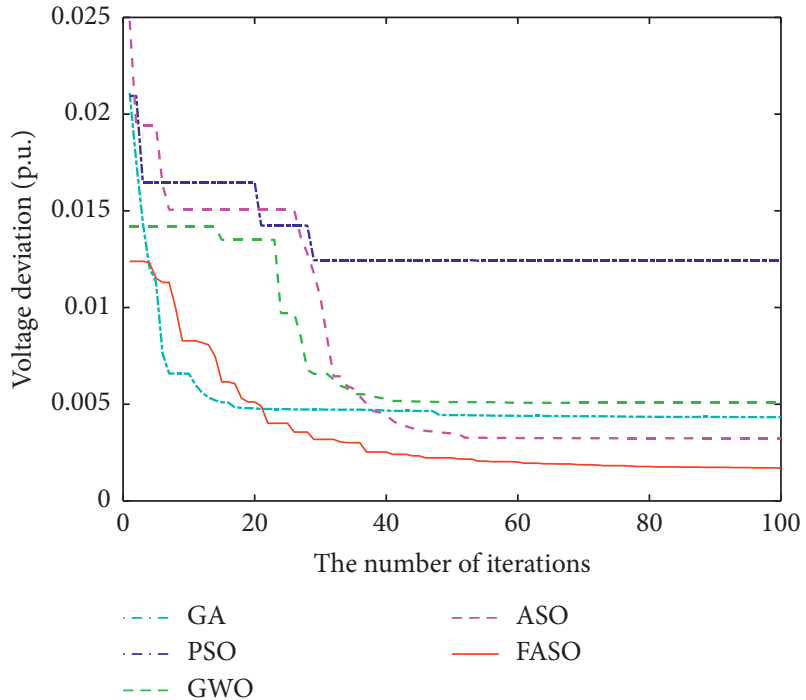

(b)

FIGURE 10: Convergence curves of RPO results obtained by different algorithms in the extended IEEE 39-bus system. (a) Power loss; (b) voltage deviation.

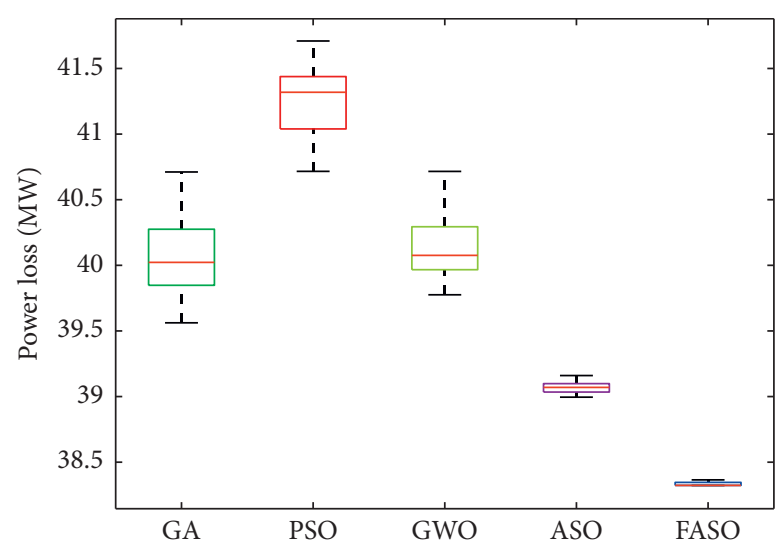

(a)

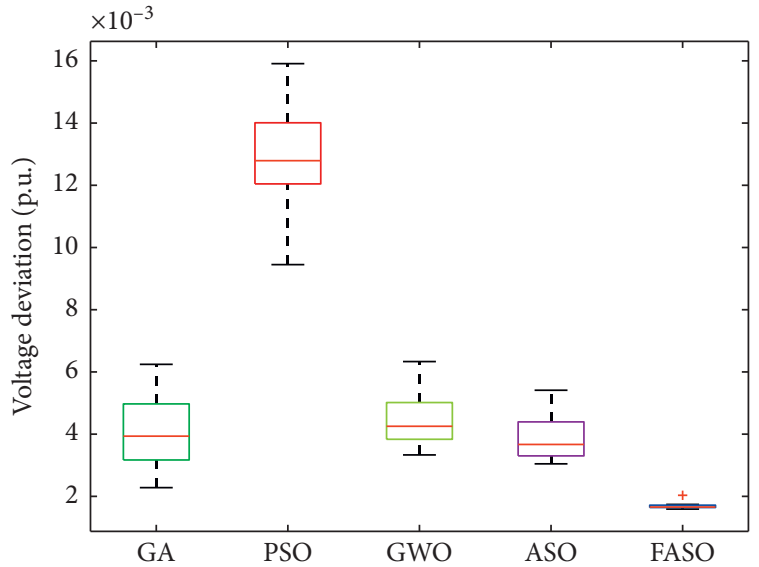

(b)

FIGURE 11: Box-and-whisker plots of RPO results obtained by different algorithms in 20 runs in the extended IEEE 39-bus system. (a) Power loss; (b) voltage deviation.

economy of the power grid with high-penetration wind and solar energies, the install locations of wind and PV generators are worth further investigating in the future.

4.3. Comparative Analysis. Table 3 provides the statistical results from five algorithms with regard to total power loss and total voltage deviation (bold indicates the best results). Note that all algorithms are executed in 20 independent runs to acquire statistical results and convergence graphs, where the best solutions are used as the optimal RPO scheme. As a result, FASO algorithm effectively avoids local optimum trapping thanks to its dynamic searching mechanism, which can maintain an appropriate tradeoff between local exploitation global exploration. Moreover, the convergence speed of the FASO algorithm can be significantly improved. Particularly, voltage deviation of FASO algorithm is merely $51.16 \%, 24.44 \%, 59.45 \%$, and $75.86 \%$ of that of GA, PSO, GWO, and ASO algorithms in the IEEE 39-bus test system, respectively. 


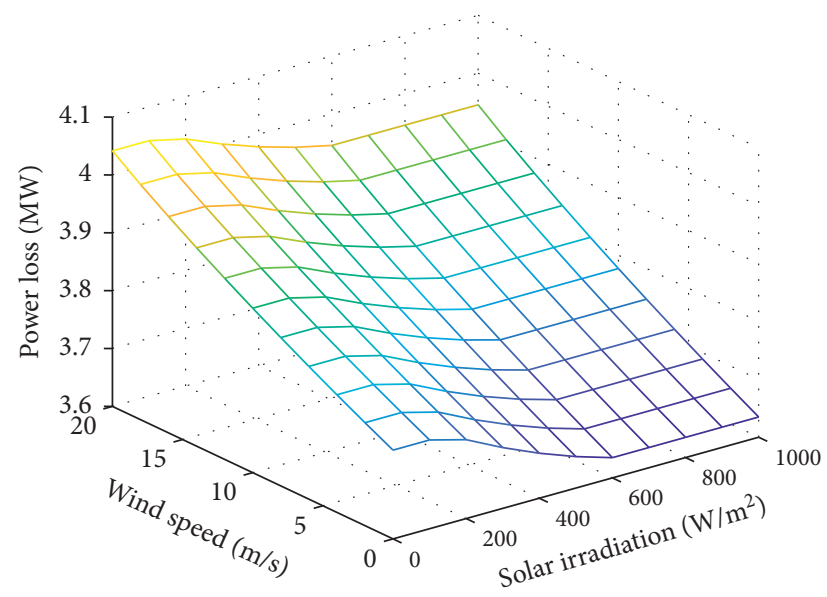

(a)

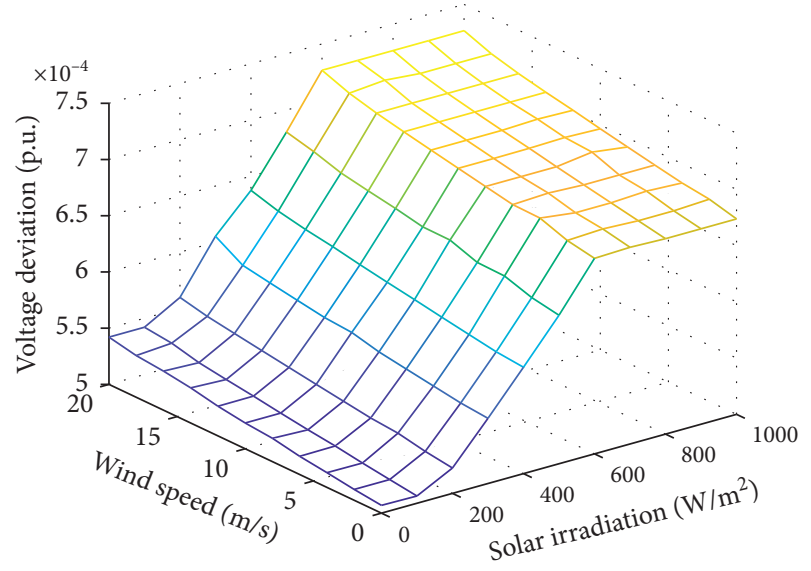

(b)

FIgURE 12: Distributions of RPO results obtained by FASO under different weather conditions of IEEE 39-bus system. (a) Power loss; (b) voltage deviation.

TABLE 3: Statistical results of convergence performance acquired by five algorithms in 20 runs.

\begin{tabular}{lcccc}
\hline Test systems & \multicolumn{2}{c}{ IEEE 9-bus } & \multicolumn{2}{c}{ IEEE 39-bus } \\
\hline Algorithms & Total power loss (MW) & Total voltage deviation (p.u.) & Total power loss (MW) & Total voltage deviation (p.u.) \\
GA & 3.9092 & $7.5853 E-04$ & 39.8906 & 0.0043 \\
PSO & 3.9352 & $8.8918 E-04$ & 41.2976 & 0.0090 \\
GWO & 3.9248 & $8.5823 E-04$ & 40.0164 & 0.0037 \\
ASO & 3.8982 & $6.7407 E-04$ & 39.2954 & 0.0029 \\
FASO & $\mathbf{3 . 8 9 0 9}$ & $\mathbf{6 . 5 0 7 0 E}-\mathbf{0 4}$ & $\mathbf{3 8 . 5 8 6 6}$ & $\mathbf{0 . 0 0 2 2}$ \\
\hline
\end{tabular}

\section{Conclusions}

This paper designs a FASO algorithm for RPO of power grid integrated with wind and solar energies, which owns the following three contributions/novelties:

(1) A new RPO model considering high-penetration wind and solar energies is established, in which the reactive power regulation ability of PV and wind generators themselves is completely developed so as to compensate reactive power for the power grid.

(2) In contrast with the original ASO algorithm, FASO can successfully realize better balance between local exploitation and global exploration via controlling the repulsion and attraction intensities among atoms based on current optimization results. Therefore, FASO can remarkably improve optimization efficiency and acquire high-quality optimum the fastest.

(3) A series of case studies are undertaken to validate the competency of the FASO algorithm for RPO, such that the total power loss and voltage deviation can be minimized in two distribution networks. Particularly, statistical results clearly showcase that FASO algorithm can find the best quality solutions with the fastest convergence speed and highest convergence stability in contrast with else algorithms.
Variables

$P_{\text {loss: }} \quad \quad \quad \quad$ Total power loss of all transmission lines

$V_{d}: \quad$ Total voltage deviation of all nodes

$P_{\mathrm{G} i}, Q_{\mathrm{G} i}: \quad$ Active and reactive power generation of node $i$

$P_{\mathrm{D} i}, Q_{\mathrm{D} i}: \quad$ Active and reactive power load

$P_{\mathrm{Gb}}: \quad$ Active power generation of slack bus

$Q_{\mathrm{G} i}{ }^{\mathrm{min}}, \quad$ The maximum and minimum reactive power

$Q_{\mathrm{G} i}{ }^{\max }: \quad$ regulation of generator

$V_{\mathrm{G} i}{ }^{\min }$, The maximum and minimum output voltage

$V_{\mathrm{G} i}{ }^{\max }: \quad$ of generator

$Q_{\mathrm{C} i}{ }^{\min }$, The maximum and minimum capacity of the

$Q_{\mathrm{C} i}{ }^{\text {max }}: \quad i$-th reactive power compensation device

$T_{h}{ }^{\text {min }}, \quad$ The lower and upper limits of the $h$-th

$T_{h}{ }^{\max }: \quad$ transformer tap

$N_{\mathrm{C}}, N_{\mathrm{T}}$ : The number of reactive power compensation devices and transformer taps

$S_{l}, S_{l}^{\max }: \quad$ Apparent power and transmission power limit of line

$T_{h}{ }^{\mathrm{min}}$, The lower and upper limits of the $h$-th

$T_{h}{ }^{\max }$ : transformer tap

$N_{C}, N_{T}$ : The number of reactive power compensation devices and transformer taps

$V_{i}^{\min }, V_{i}^{\max }$ : The lower and upper limits of voltage of node $i$ $S_{l}, S_{l}^{\max }$ : Apparent power and transmission power limit of line $l$ 


\author{
FASO parameters \\ $h_{\max }, h_{\min }$ : Maximum and minimum distance ratios \\ $n$ : $\quad$ Population size \\ $\beta$ : $\quad$ Multiplier weight \\ $\lambda$ : $\quad$ Lagrangian multiplier
}

Wind generator parameters

$L_{s}, L_{m}$ : $\quad$ Stator inductance and magnetizing inductance

$\omega_{1}$ : $\quad$ Synchronous rotational speed

$Q_{g \text {, max }}$, The lower and upper limits of reactive power

$Q_{g, \min }$ : regulation capacity for wind turbine

$S_{c \text {,max }}$ Capacity of the grid-side VSC

$P V$ generator parameters

$P_{\mathrm{pv}}^{\text {base. }} \quad$ The rated generated output of PV stations

$\alpha_{\mathrm{pv}}$ : Temperature-power conversion factor

$S_{\mathrm{pv}}$ : Current solar irradiation

$Q_{\mathrm{pv}, \max }, \quad$ The maximum and minimum reactive power

$Q_{\mathrm{pv}, \text { min }}$ : regulation capacity for PV stations

$S_{\mathrm{pv}}$ : $\quad$ the capacity of PV inverter

\section{Abbreviations}

RESs: Renewable energy sources

RPO: Reactive power optimization

FASO: Fast atom search optimization

SVC: Static VAR compensator

L-J: Lennard-Jones

GA: Genetic algorithm

PSO: Particle swarm optimization

MFO: Moth-flame optimization

GWO: Grey wolf optimizer.

\section{Data Availability}

The data that support the findings of this study are available on request from the corresponding author. The data are not publicly available due to privacy or ethical restrictions.

\section{Conflicts of Interest}

The authors declare that they have no conflicts of interest to report regarding the present study.

\section{Acknowledgments}

The authors gratefully acknowledge the support of key Project of National Natural Science Foundation of China (52037003) and Key Science and Technology Project of Yunnan Province (202002AF080001).

\section{References}

[1] B. Yang, X. Zhang, T. Yu, H. Shu, and Z. Fang, "Grouped grey wolf optimizer for maximum power point tracking of doublyfed induction generator based wind turbine," Energy Conversion and Management, vol. 133, pp. 427-443, 2017.
[2] B. Yang, T. Yu, H. Shu et al., "Passivity-based sliding-mode control design for optimal power extraction of a PMSG based variable speed wind turbine," Renewable Energy, vol. 119, pp. 577-589, 2018.

[3] D. R. Song, S. Y. Zheng, S. Yang et al., "Annual energy production estimation for variable-speed wind turbines at high-altitude sites," Journal of Modern Power Systems and Clean Energy, 2020.

[4] B. Yang, T. Yu, H. Shu, J. Dong, and L. Jiang, "Robust slidingmode control of wind energy conversion systems for optimal power extraction via nonlinear perturbation observers," Applied Energy, vol. 210, pp. 711-723, 2018.

[5] B. Yang, T. Yu, H. Shu, X. Zhang, K. Qu, and L. Jiang, "Democratic joint operations algorithm for optimal power extraction of PMSG based wind energy conversion system," Energy Conversion and Management, vol. 159, pp. 312-326, 2018.

[6] S. Mensou, A. Essadki, T. Nasser, and B. B. Idrissi, "A direct power control of a DFIG based WECS during symmetrical voltage dips," Protection and Control of Modern Power Systems, vol. 5, no. 5, pp. 36-47, 2020.

[7] D. R. Song, Q. A. Li, Z. Cai et al., "Model predictive control using multi-step prediction model for electrical yaw system of horizontal-axis wind turbines," IEEE Transactions on Sustainable Energy, vol. 10, no. 4, pp. 2084-2093, 2019.

[8] D. Song, X. Fan, J. Yang, A. Liu, S. Chen, and Y. H. Joo, "Power extraction efficiency optimization of horizontal-axis wind turbines through optimizing control parameters of yaw control systems using an intelligent method," Applied Energy, vol. 224, pp. 267-279, 2018.

[9] Y. Chaibi, A. Allouhi, M. Salhi1, and A. El-jouni, “Annual performance analysis of different maximum power point tracking techniques used in photovoltaic systems," Protection and Control of Modern Power Systems, vol. 4, no. 4, pp. 171-180, 2019.

[10] H. Hamdi, C. B. Regaya, and A. Zaafouri, "A sliding-neural network control of induction-motor-pump supplied by photovoltaic generator," Protection and Control of Modern Power Systems, vol. 4, no. 4, pp. 306-322, 2019.

[11] B. Yang, L. Zhong, X. Zhang et al., "Novel bio-inspired memetic salp swarm algorithm and application to MPPT for PV systems considering partial shading condition," Journal of Cleaner Production, vol. 215, pp. 1203-1222, 2019.

[12] B. Yang, T. Yu, X. Zhang et al., "Dynamic leader based collective intelligence for maximum power point tracking of PV systems affected by partial shading condition," Energy Conversion and Management, vol. 179, pp. 286-303, 2019.

[13] X. Zhang, S. Li, T. He et al., "Memetic reinforcement learning based maximum power point tracking design for PV systems under partial shading condition," Energy, vol. 174, pp. 1079-1090, 2019.

[14] P. K. Guchhait and A. Banerjee, "Stability enhancement of wind energy integrated hybrid system with the help of static synchronous compensator and symbiosis organisms search algorithm," Protection and Control of Modern Power Systems, vol. 5, no. 2, pp. 138-150, 2020.

[15] B. Yang, L. Jiang, W. Yao, and Q. H. Wu, "Perturbation estimation based coordinated adaptive passive control for multimachine power systems," Control Engineering Practice, vol. 44, pp. 172-192, 2015.

[16] M. Tan, C. J. Han, C. Han, X. Zhang, L. Guo, and T. Yu, "Hierarchically correlated equilibrium Q-learning for multiarea decentralized collaborative reactive power optimization," 
CSEE Journal of Power and Energy Systems, vol. 2, no. 3, pp. 65-72, 2016.

[17] X. Zhang, T. Tan, B. Zhou, T. Yu, B. Yang, and X. Huang, "Adaptive distributed auction-based algorithm for optimal mileage based AGC dispatch with high participation of renewable energy," International Journal of Electrical Power \& Energy Systems, vol. 124, Article ID 106371, 2021.

[18] M. N. I. Sarkar, L. G. Meegahapola, and M. Datta, "Optimal reactive power dispatch considering reactive power support from renewable energy generators," in Proceedings of the IEEE International Conference on Industrial Technology (ICIT), pp. 667-672, Melbourne, Australia, February 2019.

[19] M. N. I. Sarkar, L. G. Meegahapola, and M. Datta, "Reactive power management in renewable rich power grids: a review of grid-codes, renewable generators, support devices, control strategies and optimization algorithms," IEEE Access, vol. 6, pp. 41458-41489, 2018.

[20] Q. X. Chen, X. Y. Zhao, and D. H. Gan, "Active-reactive scheduling of active distribution system considering interactive load and battery storage," Protection and Control of Modern Power Systems, vol. 2, no. 2, pp. 320-330, 2017.

[21] D. Gutierrez Rojas, J. Lopez Lezama, and W. Villa, "Metaheuristic techniques applied to the optimal reactive power dispatch: a review," IEEE Latin America Transactions, vol. 14, no. 5, pp. 2253-2263, 2016.

[22] M. Ettappan, V. Vimala, S. Ramesh, and V. T. Kesavan, "Optimal reactive power dispatch for real power loss minimization and voltage stability enhancement using artificial bee colony algorithm," Microprocessors and Microsystems, vol. 76, Article ID 103085, 2020.

[23] M. N. Gilvaei, H. Jafari, M. J. Ghadi, and L. Li, "A novel hybrid optimization approach for reactive power dispatch problem considering voltage stability index," Engineering Applications of Artificial Intelligence, vol. 96, Article ID 103963, 2020.

[24] H. B. Ruan, H. J. Gao, J. Y. Liu, and Y. B. Liu, "A distributionally robust reactive power optimization model for active distribution network considering reactive power support of DG and switch reconfiguration," Energy Procedia, vol. 158, pp. 6358-6365, 2019.

[25] J. Huang, Z. Li, and Q. H. Wu, "Fully decentralized multiarea reactive power optimization considering practical regulation constraints of devices," International Journal of Electrical Power \& Energy Systems, vol. 105, pp. 351-364, 2019.

[26] M. K. Mangoli, K. Y. Lee, and Y. Moon Park, "Optimal real and reactive power control using linear programming," Electric Power Systems Research, vol. 26, no. 1, 1993.

[27] R. M. Jan and N. Chen, "Application of the fast NewtonRaphson economic dispatch and reactive power/voltage dispatch by sensitivity factors to optimal power flow," IEEE Transactions on Energy Conversion, vol. 10, no. 2, pp. 293-301, 1995.

[28] F.-C. Lu and Y. Y. Hsu, "Reactive power/voltage control in a distribution substation using dynamic programming," IEE Proceedings - Generation, Transmission and Distribution, vol. 142, no. 6, pp. 639-645, 1995.

[29] J. Z. Zhu and X. F. Xiong, "Optimal reactive power control using modified interior point method," Electric Power Systems Research, vol. 66, no. 2, pp. 187-192, 2003.

[30] N. Grudinin, "Reactive power optimization using successive quadratic programming method," IEEE Transactions on Power Systems, vol. 13, no. 4, pp. 1219-1225, 1998.

[31] S. M. Mohseni-Bonab and A. Rabiee, "Optimal reactive power dispatch: a review, and a new stochastic voltage stability constrained multi-objective model at the presence of uncertain wind power generation," IET Generation, Transmission \& Distribution, vol. 11, no. 4, pp. 815-829, 2017.

[32] B. Yang, J. Wang, Y. Chen et al., "Optimal sizing and placement of energy storage system in power grids: a state-of-the-art one-stop handbook," Journal of Energy Storage, vol. 32, Article ID 101814, 2020.

[33] K. Iba, "Reactive power optimization by genetic algorithm," IEEE Transactions on Power Systems, vol. 9, no. 2, pp. 685692, 1994.

[34] R. Bakhshi, J. Sadeh, and H.-R. Mosaddegh, "Optimal economic designing of grid-connected photovoltaic systems with multiple inverters using linear and nonlinear module models based on genetic algorithm," Renewable Energy, vol. 72, pp. 386-394, 2014.

[35] K. Ben Oualid Medani and S. Sayah, "Optimal reactive power dispatch using particle swarm optimization with time varying acceleration coefficients," in Proceedings of the 2016 8th International Conference on Modelling, Identification and Control (ICMIC), pp. 780-785, IEEE, Algiers, Algeria, November 2016.

[36] N. S. M. Rebecca, M. H. Sulaiman, M. Zuriani, and D. Hamdan, "Optimal reactive power dispatch solution by loss minimization using moth-flame optimization technique," Applied Soft Computing, vol. 59, pp. 210-222, 2017.

[37] M. H. Sulaiman, Z. Mustaffa, M. R. Mohamed, and O. Aliman, "Using the gray wolf optimizer for solving optimal reactive power dispatch problem," Applied Soft Computing, vol. 32, pp. 286-292, 2015.

[38] A. Benslimane, J. Bouchnaif, M. Essoufi, B. Hajji, and L. Idrissi, "Comparative study of semiconductor power losses between CSI-based STATCOM and VSI-based STATCOM, both used for unbalance compensation," Protection and Control of Modern Power Systems, vol. 5, no. 1, pp. 56-69, 2020.

[39] J. Li, H. Huang, B. Lou, Y. Peng, Q. Huang, and K. Xia, "Wind farm reactive power and voltage control strategy based on adaptive discrete binary particle swarm optimization algorithm," in Proceedings of the 2019 IEEE Asia Power and Energy Engineering Conference (APEEC), pp. 99-102, IEEE, Chengdu, China, March 2019.

[40] R. Sun, Y. Shu, Z. Lv, B. Chen, and Z. Wei, "Research on the multiple timescale reactive power optimization of receiving power grid based on model predictive control," in Proceedings of the 2020 12th IEEE PES Asia-Pacific Power and Energy Engineering Conference (APPEEC), September 2020.

[41] W. Zhao, L. Wang, and Z. Zhang, "Atom search optimization and its application to solve a hydrogeologic parameter estimation problem," Knowledge-Based Systems, vol. 163, pp. 283-304, 2019.

[42] B. Yang, M. Zhang, X. Zhang et al., "Fast atom search optimization based MPPT design of centralized thermoelectric generation system under heterogeneous temperature difference," Journal of Cleaner Production, vol. 248, Article ID 119301, 2020.

[43] K. Sun, W. Yao, J. Fang, X. Ai, J. Wen, and S. Cheng, "Impedance modeling and stability analysis of grid-connected DFIG-based wind farm with a VSC-HVDC," IEEE Journal of Emerging and Selected Topics in Power Electronics, vol. 8, no. 2, pp. 1375-1390, 2020.

[44] B. Yang, L. Jiang, L. Wang, W. Yao, and Q. H. Wu, "Nonlinear maximum power point tracking control and modal analysis of DFIG based wind turbine," International Journal of Electrical Power \& Energy Systems, vol. 74, pp. 429-436, 2016. 
[45] J. Hetzer, D. C. Yu, and K. Bhattarai, "An economic dispatch model incorporating wind power," IEEE Transactions on Energy Conversion, vol. 23, no. 2, pp. 603-611, 2008.

[46] M. Edrah, K. L. Lo, and O. Anaya-Lara, "Reactive power control of DFIG wind turbines for power oscillation damping under a wide range of operating conditions," IET Generation, Transmission \& Distribution, vol. 10, no. 15, pp. 3777-3785, 2016.

[47] S. Brini, H. H. Abdallah, and A. Ouali, "Economic dispatch for power system included wind and solar thermal energy," Leonardo Journal of Sciences, vol. 14, pp. 204-220, 2009.

[48] Q. Wang, W. Yao, J. Fang et al., "Dynamic modeling and small signal stability analysis of distributed photovoltaic gridconnected system with large scale of panel level DC optimizers," Applied Energy, vol. 259, Article ID 114132, 2020.

[49] J.-P. Ryckaert, G. Ciccotti, and H. J. C. Berendsen, "Numerical integration of the cartesian equations of motion of a system with constraints: molecular dynamics of n-alkanes," Journal of Computational Physics, vol. 23, no. 3, pp. 327-341, 1977.

[50] M. A. Abido, "Optimal power flow using particle swarm optimization," International Journal of Electrical Power \& Energy Systems, vol. 24, no. 7, pp. 563-571, 2002.

[51] X. Zhang, T. Yu, B. Yang, and L. Cheng, "Accelerating bioinspired optimizer with transfer reinforcement learning for reactive power optimization," Knowledge-Based Systems, vol. 116, pp. 26-38, 2017. 